\title{
A Study of Rockburst Hazard Evaluation Method in Coal Mine
}

\author{
Zhijie Wen, ${ }^{1}$ Xiao Wang, ${ }^{1}$ Yunliang Tan, ${ }^{1}$ Hualei Zhang, \\ Wanpeng Huang, ${ }^{1}$ and Qinghai $\mathrm{Li}^{1}$ \\ ${ }^{1}$ State Key Laboratory of Mining Disaster Prevention and Control Cofounded by Shandong Province and the Ministry of \\ Science and Technology, Shandong University of Science and Technology, Qingdao, Shandong 266590, China \\ ${ }^{2}$ School of Energy and Safety, Anhui University of Science \& Technology, Huainan, Anhui 232001, China
}

Correspondence should be addressed to Yunliang Tan; tylllp@163169.net and Qinghai Li; li-qinghai@163.com

Received 15 December 2015; Accepted 14 March 2016

Academic Editor: Carlo Rainieri

Copyright (C) 2016 Zhijie Wen et al. This is an open access article distributed under the Creative Commons Attribution License, which permits unrestricted use, distribution, and reproduction in any medium, provided the original work is properly cited.

\begin{abstract}
With the increasing of coal mining depth, the mining conditions are deteriorating, and dynamic hazard is becoming more likely to happen. This paper analyzes the relations and differences between rockburst in the coal mine and rockburst in the metal mine. It divides coal mine rockburst into two types including static loading type during roadway excavation process and dynamic loading type during mining face advancing. It proposes the correlation between the formation process of rockburst and the evolution of overlying strata spatial structure of the stope, criterion of rockburst occurrence, new classification, and predictive evaluation method for rockburst hazard that rockburst damage evaluation $(\mathrm{RDE})=$ released energy capacity (REC)/absorbed energy capacity (AEC). Based on the relationship between RDE value and its corresponding level of rockburst hazard, the rockburst hazard can be divided into five types and evaluation index of each type can be achieved. Then the ongoing rockburst damage level can be classified in one of the five types, and the relative parameters, such as hazard extent, controlling measures also can be achieved. This new quantitative method could not only assess the impacting direction of rockburst occurrence, but also verify the effect of preventive measures for rockburst.
\end{abstract}

\section{Introduction}

With the increasing mining depth and mining intensity, dynamic hazard, such as rockburst, is becoming more likely to happen, which threatens the safe and high-efficient mining [1-3]. According to the statistics [4-7], foreign mining of over 1000-meter deep metal mines has more than 80 seats, of which, up to South Africa, Anglogold Limited Liability Company's western deep gold mine, mining depth up to $3700 \mathrm{~m}$, and India Kolar gold mining area have three gold mining depths of more than $2400 \mathrm{~m}$; Driefovten West gold deposit occurred in the underground $600 \mathrm{~m}$ extended to 6000 m; Krivoy Rog Russia's iron ore district has Dzerzhinsky, akilov, Communist International, and other 8 mines, mining depth of $910 \mathrm{~m}$, to explore the depth of $1570 \mathrm{~m}$, which is expected to reach $2000-2500 \mathrm{~m}$. In China, there were 32 coal mines in which rockburst occurred in 1985, and the amount of such coal mines was up to 142 in 2012. Meanwhile, there are more than 50 coal mines with the mining depth of more than $1000 \mathrm{~m}$. During the period of 2006-2013, more than nine coal mines, like Xinwen coal mine, Yima coal mine, and so forth, had occurred 35 times rockburst, 300 people died, and more than one thousand people were injured in these accidents. The degree of damage in coal mine rockburst is becoming increasingly severe.

With addition of the complexity of mining geological condition, the problem of rockburst is particularly acute, so a scientific solution to predict and control the rockburst is urgently needed.

\section{Definition and Classification of Rockburst in Coal Mine}

2.1. Definition of Rockburst in Coal Mine. Rockburst in coal mine is a dynamic phenomenon with sudden severe damage, throw-out of large quantity of rock or coal body, and loud sound in the surrounding rock of roadway or working face, which is induced by instantaneous release of elastic deformed energy of the surrounding rock and occurs during the mining 
process. It usually leads to severe supporting device damage and large deformation in the roadway and working face, casualties and coal mine collapse in the worse situation, and even ground collapse that induces local earthquake. It is one of major hazards in coal mine $[8,9]$. The typical characteristics in the coal mine rockburst are as follows. For the occurrence time, it usually occurs during the large-area working face weighting period induced by the upper hard roof breaking; for the occurrence area, it usually occurs in the high stress area 100 meters in front of working face; for the reason of rockburst occurrence, it is usually induced by dynamic impact like impact of hard roof breaking and blasting; for the appearances of the coal mine rockburst, it usually leads to up to $90 \%$ of reduction ration of roadway section or the mining equipment damage like working face supports.

Rockburst in metal mine or underground tunnel occurs in the geological condition of high stress area and is a dynamic phenomenon of rock crack and damage or rock ejection induced by the sudden release of rock mass stored elastic energy during the excavation process [10, 11]. The typical characteristics of rockburst in the mental mine or underground tunnel are as follows. It usually occurs with obvious sound. The level of sound depends on the level of rockburst; the obvious feature of rock damage attitude is sheet; its occurrence is related to the direction of tectonic stress.

Considering economic factors and temporary requirements, deformation or little damage of the surrounding rock is allowed in coal mining projects, as long as the structure of the surrounding rock does not fail and meets the production safety requirements. Underground tunneling projects do not allow big deformation or little damage. Moreover, mininginduced stress is another characteristic in coal mine, which is much bigger than that of underground tunneling projects.

The similar parts between rockburst in coal mine and rockburst in metal mine or underground tunnels are a dynamic phenomenon with rock breaking and throw-out because of sudden release of surrounding rock stress. The difference between them is that, in mining engineering, the sign of rockburst occurrence depends on whether this dynamic phenomenon can induce serious damage and geological hazard or not. With no serious damage or geological hazard, the treatment measures are not needed. So the dynamic failure phenomenon which needs to be taken in treatment measures in coal mine is called rockburst, and its hazard evaluation criterion should be the induced serious damage and the geological hazard.

2.2. Main Factors in Rockburst Mines. Many researchers propose different classification methods of rockburst from different perspectives. According to the position of rockburst occurrence, coal mine rockburst is divided into three types including rockburst of coal seam, rockburst of roof, rockburst of floor. According to the energy source of rockburst, it is divided into the gravitative type, the tectonic type, and gravitative-tectonic type. According to the magnitude of impact energy, it is divided into microimpact type, weak

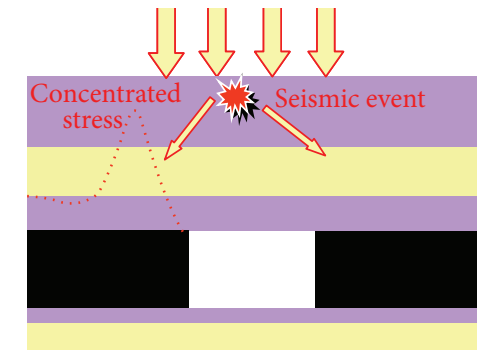

FIGURE 1: Mechanical structure of static loading type during roadway excavation.

impact type, medium impact type, strong impact type, and disastrous impact type. Based on loading type of coal or rock material and their failure models, rockburst is divided into static load-induced stress type of burst failure and dynamic load-induced vibration type of burst failure [12].

Pan et al. summarize and analyze crucial influencing factors of 67 coal mines where rockburst had occurred in the recent 5 years in China. The statistics of geological factors and technical factors for rockburst prone mines are shown in Table 1 [13]. The geological factors mainly include hard and thick roof, overlying strata with large thickness, hard roof-and-floor, geological structure, great inclined coal seam, change of coal thickness, and natural earthquake. The technical factors mainly include gob-surrounded coal pillar, upper coal pillar formed in the mining coal seam group, and blast-induced vibration.

This paper, based on the energy viewpoint, redivides the coal mine rockburst into two types including static loading type during roadway excavation mainly induced by the compressive elastic energy release of coal seam (Figure 1) and dynamic loading type during mining face advancing mainly induced by elastic stored energy release of overlying strata in the stope (Figure 2). In Figure 2, the dynamic pressure is generated by the whole process of overlying strata breaking. Whether it is static loading type or dynamic loading type, the occurrence of rockburst is related to unreasonable mining distribution design, which leads to mining stress concentration in certain partial area and overlimits accumulation energy of coal body. So the distribution of mining stress should be considered in the prediction and prevention of coal mine rockburst.

\section{Formation Process of Rockburst and Movement of Overlying Strata Spatial Structure of the Stope}

3.1. Mechanism of Rockburst Occurrence. For high strength coal or rock seam, high level elastic stored energy and high level stress concentration induced by tectonic movement and mining face advancing are the root cause of coal mine rockburst $[14,15]$. Without preventive measures of stress and energy releasing, rockburst most probably occurs in the positions of high level stress concentration and elastic stored energy when the working face advances. 
TABLE 1: Statistics of main factors in rockburst mines [13].

\begin{tabular}{|c|c|c|}
\hline Geological factors & $\begin{array}{l}\text { Amount of } \\
\text { rockburst mines } \\
(2008-2013)\end{array}$ & Typical examples \\
\hline Hard and thick roof & 48 & $\begin{array}{l}\text { Dongtan and Baodian coal mines; Liangzhuang, Xiezhuang, and Panxi coal mines; } \\
\text { Sanhejian coal mine; number } 11 \text { and number } 12 \text { coal mines in Pingdingshan; } \\
\text { Tangshan coal mine; Junde and Nanshan coal mines; Xinxing coal mine }\end{array}$ \\
\hline $\begin{array}{l}\text { Overlying strata with large } \\
\text { thickness }\end{array}$ & 5 & Huafeng coal mine; Qianqiu coal mine; Shijie coal mine; Wanglou coal mine \\
\hline Hard roof-and-floor & 6 & $\begin{array}{l}\text { Tongjialiang and Xizhouyao coal mines; Huafeng and Suncun coal mines; } \\
\text { Hetaoshan coal mine; Yanbei coal mine }\end{array}$ \\
\hline Geological structure & 38 & $\begin{array}{l}\text { Laohutai coal mine; Sunjiawan coal mine; Guantai coal mine; Tangshan and } \\
\text { Zhaogezhuang coal mines; Panxi coal mine }\end{array}$ \\
\hline Great inclined coal seam & 3 & Huating coal mine; Muchengjian coal mine; Huafeng coal mine \\
\hline Change of coal thickness & 2 & Jisan coal mine; Xiezhuang coal mine \\
\hline Natural earthquake & 1 & Zhaogezhuang coal mine \\
\hline Gob-surrounded coal pillar & 26 & $\begin{array}{l}\text { Qianqiu coal mine; Jisan, Dongtan, Baodian, and Jiyi coal mines; Xiezhuang coal } \\
\text { mine; Zhuangji coal mine; number } 11 \text { coal mine in Pingdingshan; Tangshan and } \\
\text { Zhaogezhuang coal mines }\end{array}$ \\
\hline $\begin{array}{l}\text { Upper coal pillar formed in } \\
\text { the mining coal seam group }\end{array}$ & 11 & Huafeng coal mine; Tongjialiang and Xizhouyao coal mines; Junde coal mine \\
\hline Blast-induced vibration & 6 & $\begin{array}{l}\text { Liangzhuang coal mine; Zhaogezhuang coal mine; Nanshan coal mine; } \\
\text { Muchengjian coal mine }\end{array}$ \\
\hline
\end{tabular}

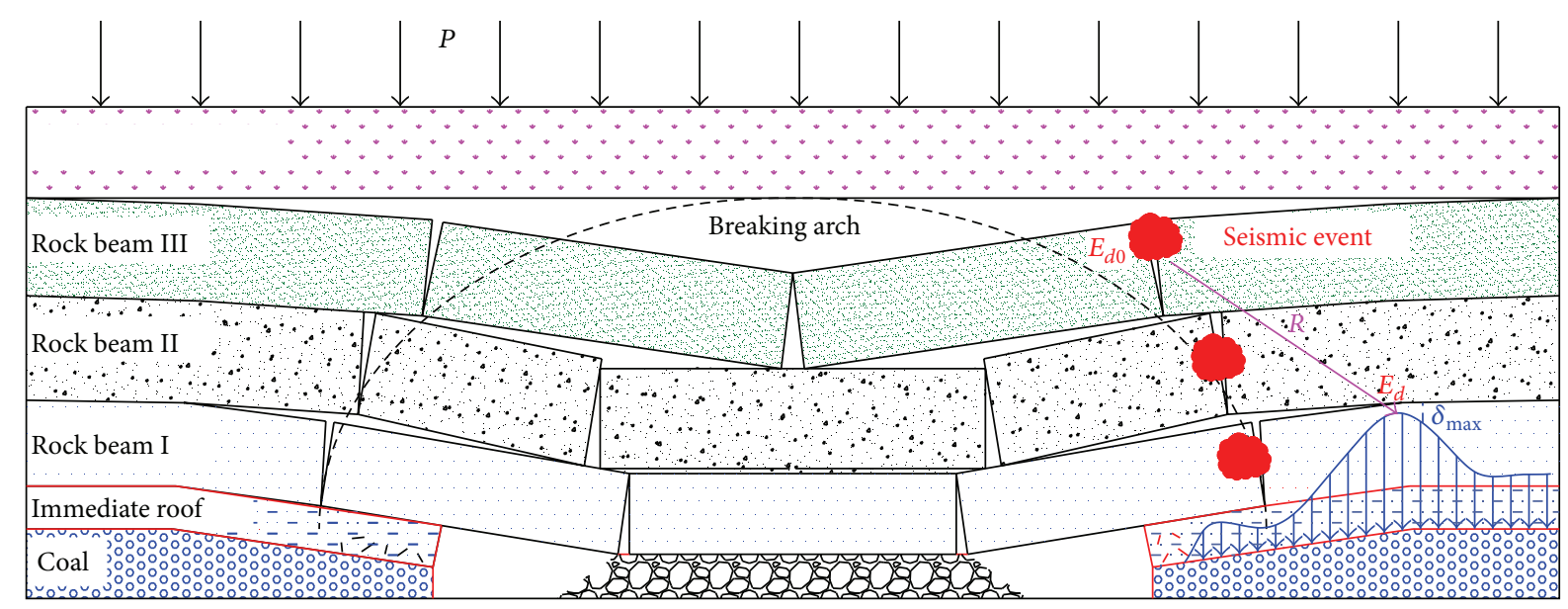

FIGURE 2: Mechanical structure of dynamic loading type during mining face advancing.

In the mining process of deep mines, dynamic evolution and development of stress field and energy field create conditions for the formation, occurrence, and development of rockburst. Rockburst is an energy-releasing process with instability in time and nonuniformity in space. Namely, from the time perspective, if the energy releasing rate in coal or rock body is greater than energy consumption rate, then the process of system failure is instable [16]. From the space perspective, the energy releasing amount at different points forms the gradient of energy releasing in space. Under the condition of the same total releasing energy, if the releasing energy distribution in the space is nonuniform and it concentrates on one or several points, the releasing energy at these points may overcome the resistance of the surrounding rock or coal body; then dynamic hazards, like rockburst, occur. In the mining conditions of deep coal mine with high stress and strong disturbance, the space-time evolution process of energy field in mining space directly determines the characteristics and formation condition of rockburst. This viewpoint about the energy field of rockburst will be helpful to study regional monitoring technology, such as microseismic monitoring technology.

3.2. Relationship between Rockburst and Evolution of Overlying Strata Structure of the Stope. Rockburst occurrence depends mainly on impacting properties and stress state of rock or coal body. Bursting proneness is the internal property of coal or rock body, which can be obtained from 


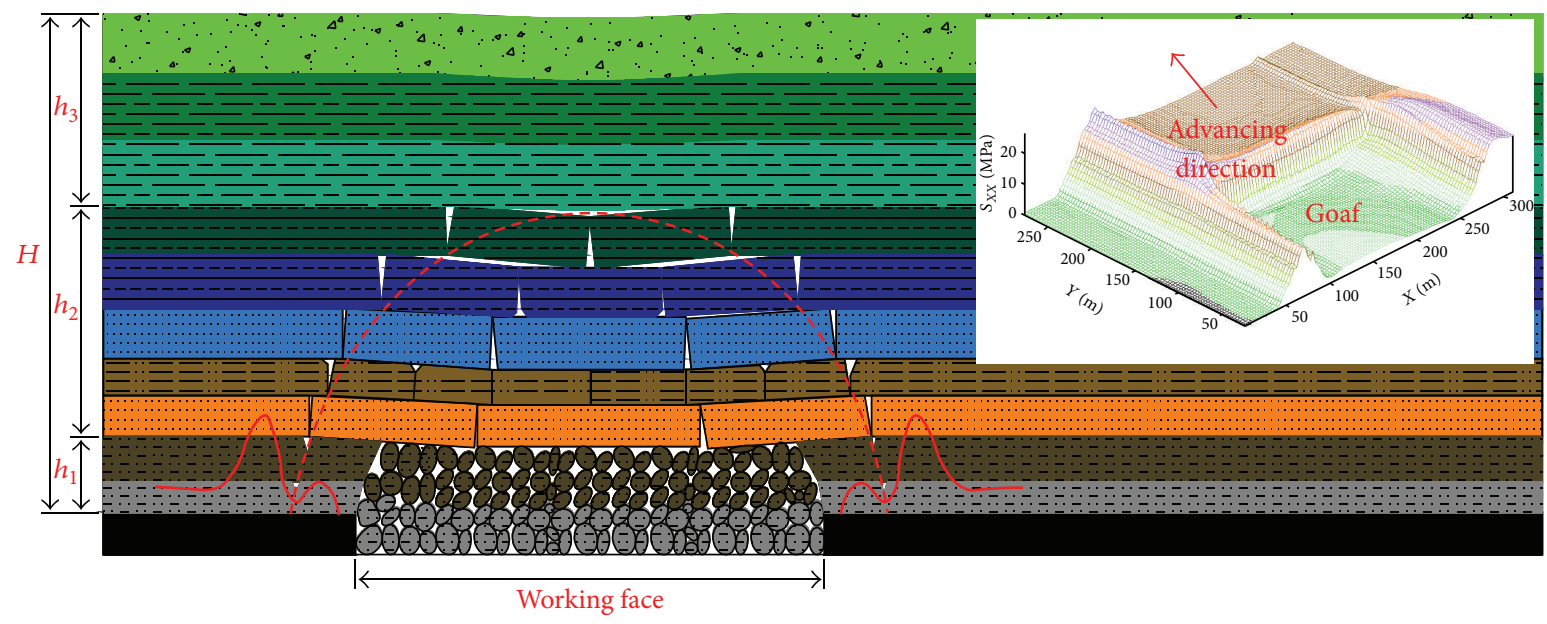

Figure 3: Structural model of the stope.

the laboratory test. Mining stress is the dynamic factor for rockburst occurrence. Rockburst usually occurs in intake or return airway close to the working face. Its range is between zero and 80 meters in front of working face. The movement of overlying strata in the stope leads to stress redistribution, which may result in instability of the surrounding rock and the occurrence of mine dynamic hazard. The evolution of mining stress is a dynamic process and is related to the advancing distance of working face, coal mining method, geological structure and distribution, and characteristics of overlying strata spatial structure.

With the development of overlying strata spatial structure in the stope, there are two characteristics of mining stress distribution, including first weighting of overlying strata and periodic weighting of working face advancing, during the formation process of breakage arch that consists of the overlying strata. With overlying strata breaking, each hard roof weighting will impact high-level stress concentration zone, which possibly leads to bursting failure. The breakage arch usually consists of several groups of hard roof. So, in order to scientifically and quantitatively study the bursting proneness of high stress zone with mining disturbance, bursting hazard for every group of hard roof rupture should be evaluated, as shown in Figure $3 . h_{1}$ stands for the height of caving zone; $h_{2}$ stands for the height of fractured zone; $h_{3}$ stands for the height of sagging zone; $H$ stands for covering depth.

3.2.1. Criterion of Rockburst Occurrence for Static Loading Type during Roadway Excavation. In Figure 2, $\delta_{\max }$ represents the maximum value of surrounding rock stress. According to minimal energy principle of rock mass dynamic failure, the energy needed in the breaking process of rock mass under the mechanical condition of one-dimensional stress state, two-dimensional stress state, or three-dimensional stress state, equals the consumption energy of rock mass rupture under the mechanical condition of one-dimensional stress state. So, failure condition for instability rupture of main bearing zone in roadway sides is that, whether it is uniaxial compressive failure or shear failure, the stress exceeds the uniaxial compressive strength or shear strength, namely, $\sigma>$ $\sigma_{c}$ or $\sigma>\tau_{c}$. The corresponding energy consumption criterion is given by [17]

$$
\begin{aligned}
E_{c} & =\frac{\sigma_{c}^{2}}{(2 E)} \\
\text { or } E_{c} & =\frac{\tau_{c}^{2}}{(2 G)},
\end{aligned}
$$

where $E_{c}$ is the consumption energy needed in the coal or rock body rupture, $\sigma_{c}$ is the rock uniaxial compressive strength, and $\tau_{c}$ is the rock shear strength.

At the position of maximum value of surrounding rock stress, the energy condition for rockburst occurrence is not only the concentrated static load, but also the accumulated elastic strain energy which is greater than minimum energy needed in the rupture process of coal or rock body. The impacting energy $\left(E_{d}\right)$ transmits to the roadway space through the medium and carrier of shallow coal body in the roadway sides, which destroys the roadway, working face, and equipment. The energy criterion for rockburst occurrence is given by

$$
E_{d}-E_{c}>0
$$

3.2.2. Criterion of Rockburst Occurrence for Dynamic Loading Type during Mining Face Advancing. Mechanical structure of dynamic loading rockburst during mining face advancing is shown in Figure 3. During the advancing process of working face, compressive elastic energy of coal seam is concentrated due to large area hanging overlying strata applied on the coal seam. Meanwhile, elastic energy is stored in the roof due to the bending deformation of high strength and big thickness hard roof. When hanging overlying strata is long enough, it will break, the compressive elastic energy in the coal seam will be released, and then the rockburst occurs. The smaller the distance of working face and neighboring roadway and centrum is, the more dangerous the impacting failure and 
corresponding accidents are, because the releasing energy from the centrum decreases progressively in the process of transmission.

From Figure 2, the impacting energy $E_{d}$ transmits from roof rupture-induced elastic energy to limit equilibrium area of coal wall which is given by

$$
E_{d}=E_{d 0} R^{-\eta},
$$

where $E_{d 0}$ is the initial releasing energy induced by roof rupture, which can be obtained by the microseismic monitoring, $R$ is the distance of the position of roof rupture and limit equilibrium area of coal wall, which can be obtained by microseismic positioning calculation, and $\eta$ is the energy damping index when the elastic wave travels through rock or coal mass.

The energy condition of rockburst occurrence is that the sum of elastic strain energy accumulated in the limit equilibrium area and dynamic loading energy from the roof rupture should be greater than the minimum energy needed in the rupture process of coal or rock mass. The criterion is given by

$$
E_{0}+E_{d}-E_{c}>0
$$

where $E_{0}$ is the accumulated energy in the investigated area representing the stress state in the area under investigation, $E_{d}$ is impacting energy generated by seismic event monitored during mining, and $E_{c}$ is the consumption energy needed in the coal body rupture.

\section{Assessment and Preventive Process of Rockburst Hazard}

Many researchers study the mechanism of rockburst by using strength theory, energy theory, damage and fracture theory, and catastrophe theory. According to these mechanisms, they further study the criterion of rockburst occurrence. The criteria used widely include E. Hoek method that uses the ratio of shear stress of coal wall and uniaxial compressive strength of rock as a criterion, Kidybinski method that uses stored energy, Hou F. L. critical covering depth method, Tao Z. Y. method that uses the ratio of uniaxial strength and maximum principal stress, and analogical method of surrounding rock classification [18]. Due to the various and complex reasons of rockburst, using a single factor to predict the rockburst is not appropriate. Based on the information mentioned above, rockburst is closely related to the mining stress distribution and mining disturbance, so multifactors comprehensive evaluation method including mining stress and mining disturbance should be built.

\subsection{Rockburst Damage Potential Evaluation Methodology.} The magnitude of the seismic event causing the damage should be considered, and whether or not a damaging seismic event is likely to occur at all should be considered also. Meanwhile, it is necessary to consider the distance from the event source to the damage location. It shows that when a significant dynamic load on an excavation occurs (after a rockburst), there is a relation between the seismic events disturbance and the degree of absorbing energy ability.

4.1.1. Released Energy Capacity (REC). Rockburst damage is known to be highly variable. For any given seismic event at a given distance from an excavation, there can be considerable variation in the amount of rockburst damage. Released energy capacity describes the relationship between the elevated energy condition due to seismic events and the general accumulated energy in the investigated area:

$$
\begin{aligned}
\mathrm{REC} & =\frac{E_{1}}{E_{2}} \times 10^{2}=\frac{E_{d}+E_{0}}{E_{0}} \cdot \frac{\sigma_{\max }}{\sigma_{\text {uniaxial }}} \times 10^{2} \\
& =\left(1+\frac{E_{d 0} \cdot e^{-\varphi R}}{E_{0}}\right) K \times 10^{2},
\end{aligned}
$$

where $E_{d}$ is the evaluated energy condition due to seismic events based on the seismic wave propagation at distance $R$ from the seismic source in viscoelastic homogenous medium, $E_{0}$ is the accumulated energy in the investigated area representing the stress state in the area under investigation, $\varphi$ is the attenuation coefficient, $K$ is the relation of, and $R$ is distance to seismic cluster.

The evaluated energy condition is based on seismic wave energy propagation at distance $R$ from the seismic source. Accumulated energy (induced stress) in the investigated area is tested by stress sensors. In situ stress measurements have been performed through an application of overcoring technique.

4.1.2. Absorbed Energy Capacity (AEC). AEC is represented by a rating scale dependent on installed support. Absorbed energy capacity equation includes the current installed reinforcement and its support load capacity in the risk estimations. The higher the capacity of the support to withstand dynamic damage, the larger the AEC. It is considered to account for the energy absorbing level of the rock support in the seismic rock failure process:

$$
\mathrm{AEC}=\frac{E_{3}}{E_{4}}=\frac{P_{s}}{P_{\text {local }}},
$$

where $E_{3}$ is absorbing energy of the installed reinforcement per square meter, $E_{4}$ is release energy in the anchorage area, $P_{s}$ is the maximum support load of the installed reinforcement per square meter, and $P_{\text {local }}$ is measured/estimated local stress in the anchorage area.

In general, it is difficult to calculate the real local stress in the anchorage area because of lack of high accuracy instrumentation. Therefore, the absorbed energy capacity (AEC) can be evaluated using qualitative scale of ground support capacity that represents basic support types in coal mine (see Table 2).

The scale of projected damage determines the necessary dynamic capacity of installed ground support. Proper ground reinforcement that can withstand dynamic loading and large deformations is required in order to reduce the rockburst hazard and protect worker and mine infrastructure and sustain safe operation [19]. 
TABLE 2: Absorbed energy capacity scale for ground support.

\begin{tabular}{lc}
\hline Support type & AEC rating \\
\hline No bolts & 1 \\
Rock bolts & 2 \\
Cable bolts & 3 \\
Rock bolts and cable bolts & 4 \\
Rock bolts and mesh & 5 \\
Rock bolts, cable bolts, and mesh & 6 \\
\hline
\end{tabular}

The presented formula will be applied on real seismic data for the first time in coal mine. The obtained results must be evaluated and classified for their risk potential. Therefore, documented damaging events due to seismic activities in the coal mine will be used for general identification purposes. Nevertheless, further assessments with detailed result interpretation and benchmarking should be carried out to verify the assessment formula/approach.

4.1.3. Rockburst Damage Evaluation (RDE). To consider the likely magnitude and the distance of the seismic event responsible for rockburst damage, the REC index can be combined with the AEC. For assessing rockburst risk, the amount of seismic event energy can be used, which is directly obtained from the seismic events testing system. The combination of the two parameters is termed "rockburst damage evaluation" (RDE).

Based on probabilistic analysis of over 120 instances of rockburst damage, $\mathrm{RDE}$ values for which certain levels of rockburst damage are expected to occur are given. The rockburst damage was categorized using Table 3 . The detailed value of RDE should be referenced by a specified mine.

4.2. Analysis of Typical Cases. During the advancing process of working face number 9103 in Junde coal mine, the equipment had monitored 118 times microseismic phenomenon, five of which are rockburst that threw a large amount of rock or coal mass out and threatened mine safety production. Combined with microseismic monitoring data, we studied the energy, magnitude, and frequency of microseismic events before and after the rockburst.

4.2.1. Mining Geologic Condition. Working face number 9103 in Junde coal mine uses slicing mining and fully mechanized coal mining for the first layer. Its mining height is $3.5 \mathrm{~m}$. It is about $300 \mathrm{~m}$ in depth and has $40 \mathrm{~m}$ thickness of hard sandstone roof in the overlying strata and protective coal pillar with the width of 5 to $40 \mathrm{~m}$. The width of working face is $150 \mathrm{~m}$. The behavior of rock pressure is serious during the mining process. The spatial distribution of microearthquake and previous rockburst is shown in Figures 4, 5, and 6.

4.2.2. Rockburst Damage Evaluation Calculation. According to the information on the previous rockburst in working face number 9103, the evaluation index of rockburst damage potential level for Junde coal mine is built. The previous

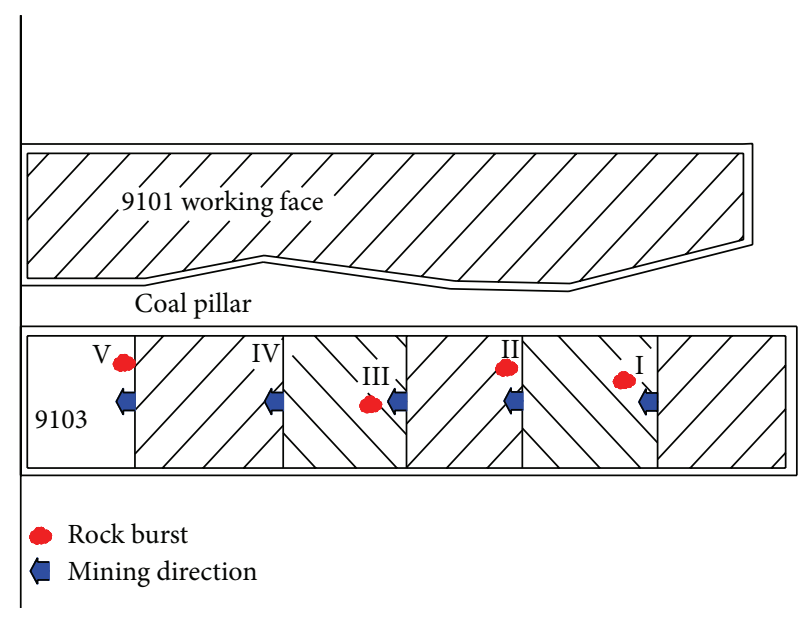

FIGURE 4: Spatial relation between microearthquake and mining.

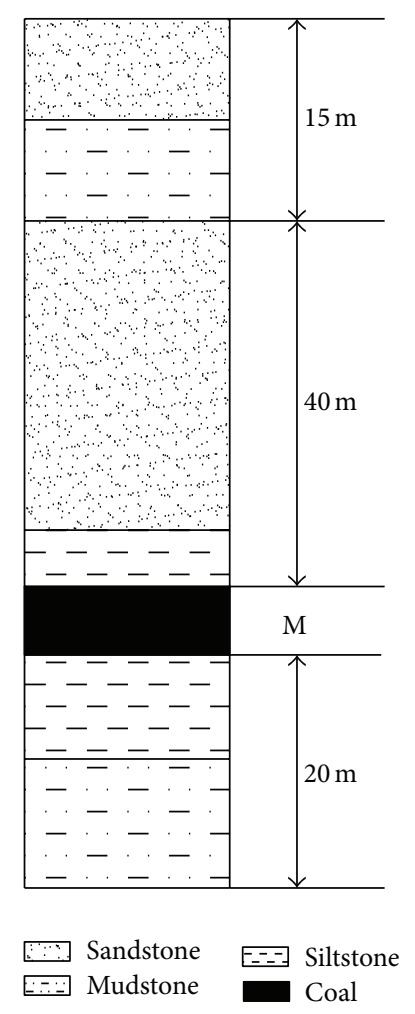

FIGURE 5: Rock strata histogram.

rockburst in different roadway with same supporting method of bolt-mesh-cable support is shown in Tables 4 and 5 .

Based on the RDE value shown in Table 5 and its corresponding damage level, the threshold of each rockburst damage potential level can be determined, as shown in Table 6. In the following mining activities, we can apply this classification method to evaluate each seismic event damage degree to mining space, including instruments and personnel. 
TABLE 3: Rockburst damage potential scale.

\begin{tabular}{|c|c|c|c|}
\hline $\mathrm{RDE}$ & $\begin{array}{c}\text { Rockburst } \\
\text { damage scale }\end{array}$ & Expected working space damage & Expected support damage \\
\hline$(a, b)$ & $R_{0}$ & No damage/minor deformation & $\begin{array}{l}\text { No damage/minor } \\
\text { deformation }\end{array}$ \\
\hline$(b, c)$ & $R_{1}$ & $\begin{array}{l}\text { Low reduction ratio of roadway section }(0 \sim 20 \%) \text {, with normal } \\
\text { production }\end{array}$ & $\begin{array}{c}\text { Support system is loaded, } \\
\text { with loose mesh and plates } \\
\text { deformed }\end{array}$ \\
\hline$(c, d)$ & $R_{2}$ & $\begin{array}{c}\text { Medium reduction ratio of roadway section }(20 \% \sim 40 \%) \text {, with a small } \\
\text { influence on normal production }\end{array}$ & Some broken bolts \\
\hline$(d, f)$ & $R_{3}$ & $\begin{array}{c}\text { Big reduction ratio of roadway section }(40 \% \sim 80 \%) \text {, with a big } \\
\text { influence on normal production }\end{array}$ & $\begin{array}{l}\text { Major damage to support } \\
\text { system }\end{array}$ \\
\hline$(f, g)$ & $R_{4}$ & $\begin{array}{l}\text { Huge reduction ratio of roadway section ( } 80 \% \sim 100 \%) \text {, with a serious } \\
\text { influence on normal production even stopping production }\end{array}$ & $\begin{array}{l}\text { Complete failure of support } \\
\text { system }\end{array}$ \\
\hline
\end{tabular}

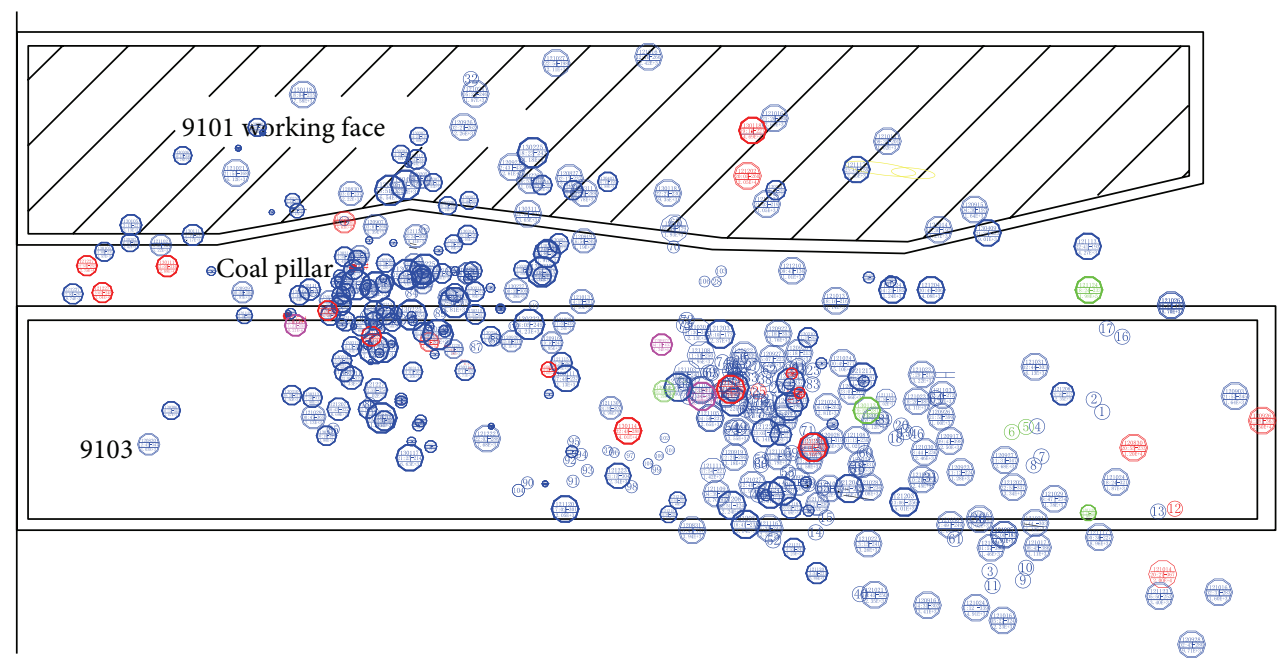

FIGURE 6: Diagram of microearthquake.

\begin{tabular}{lcc}
\hline Energy & Energy & Color \\
\hline $1.00 E+01$ & Yellow \\
$1.00 E+02$ & Purple \\
$1.00 E+03$ & Blue \\
$1.00 E+04$ & Red \\
$1.00 E+05$ & Green \\
$1.00 E+06$ & Magenta \\
$1.00 E+07$ & Black \\
\hline
\end{tabular}

Different RDE values can be obtained by putting the five event times into the RDE formula. According to the hazard level in combination with the monitored microearthquake events, the rockburst damage potential classification for other working faces can be predicted, especially for the same mining area.

\section{Conclusions}

Rockburst occurrence is closely related to the accumulated energy in the impacting zone. Based on the energy factor, it can be divided to two types including static load type during roadway excavation and dynamic load type during mining face advancing. The first is induced when the roadways excavate high concentration area of tectonic stress. The second occurs when the bending deformation that stored elastic energy of overlying strata induces the compressive elastic energy of coal seam. Compressive elastic energy of coal seam is concentrated due to large area hanging overlying strata applied on the coal seam. Elastic energy of overlying strata is stored in the roof due to the bending deformation of high strength and big thickness hard roof.

The formation process of rockburst during the advance of working face is related to the movement of overlying strata of the stope. The impacting energy generated in hard roof when breaking exceeds the upper limit energy that is stored in stress concentrated area. The criteria for static load type during roadway excavation and dynamic load type during the advance of mining face are built; that is, $E_{d}=E_{d 0} R^{-\eta}$ when excavating roadway and $E_{0}+E_{d}-E_{c}>0$ when mining.

The quantitative method to evaluate and predict rockburst damage evaluation level was studied based on the existing rockbursts' parameters and its hazard appearance. The rockburst is divided into five levels with different RDE values by using the influence of hard roof rupture process on the disturbance of energy accumulated in the area, in combination with previous microearthquake and rockburst events in the mining area. Then the ongoing rockbursts' hazard level can be predicated. 
TABLE 4: Statistics of previous rockburst in Junde coal mine.

\begin{tabular}{lccccccc}
\hline RDE & AEC & REC & $E_{D} / J$ & $E_{0} / \mathrm{MJ}$ & $\mathrm{EXP}(-\varphi R)$ & $R / \mathrm{m}$ & $\begin{array}{c}\text { Coefficient of stress } \\
\text { concentration “ } K \text { ” }\end{array}$ \\
\hline 5.09 & 5.00 & 2.54 & 220000 & 60 & 0.74 & 30.00 & 2.00 \\
4.56 & 5.00 & 2.28 & 126000 & 60 & 0.67 & 40.00 & 2.00 \\
3.22 & 5.00 & 1.61 & 36700 & 30 & 0.61 & 50.00 & 1.50 \\
9.27 & 5.00 & 4.64 & 936000 & 30 & 0.67 & 40.00 & 1.50 \\
6.72 & 5.00 & 3.36 & 578000 & 60 & 0.70 & 35.00 & 2.00 \\
4.28 & 5.00 & 2.14 & 63600 & 60 & 0.67 & 40.00 & 2.00 \\
\hline
\end{tabular}

TABLE 5: Characteristics of rockburst.

\begin{tabular}{|c|c|c|c|c|c|c|c|c|}
\hline Number & Time & $\begin{array}{c}\text { Energy of } \\
\text { centrum } E_{d} / \mathrm{J}\end{array}$ & $\begin{array}{c}\text { Accumulated } \\
\text { energy } E_{c} / \times 10^{6} \mathrm{~J}\end{array}$ & $\begin{array}{l}\text { Distance from } \\
\text { rockburst to } \\
\text { centrum } R / \mathrm{m}\end{array}$ & $\begin{array}{l}\text { Characteristics } \\
\text { of rockburst }\end{array}$ & Reason & $\begin{array}{l}\text { Type of } \\
\text { rockburst }\end{array}$ & $\mathrm{RDE}$ \\
\hline 1 & $\begin{array}{l}\text { Aug. 30, } \\
2012\end{array}$ & $2.2 E+05$ & 60 & 30 & $\begin{array}{c}50 \mathrm{~m} \text { in front of } \\
\text { working face; } \\
\text { roof-to-floor } \\
\text { convergence of } \\
0.6 \mathrm{~m} \text {, rib sides } \\
\text { convergence of } \\
1.2 \mathrm{~m} \\
\end{array}$ & $\begin{array}{l}\text { Accumulated } \\
\text { energy releasing } \\
\text { of coal pillar } \\
\text { induced by first } \\
\text { weighting of } \\
\text { hard roof }\end{array}$ & $\begin{array}{l}\text { Dynamic load } \\
\text { type during } \\
\text { mining face } \\
\text { advancing }\end{array}$ & 5.09 \\
\hline 2 & Jan. 9, 2013 & $1.26 E+05$ & 60 & 40 & $\begin{array}{l}40 \mathrm{~m} \text { in front of } \\
\text { working face; } \\
\text { roof-to-floor } \\
\text { convergence of } \\
0.7 \mathrm{~m} \text {, rib sides } \\
\text { convergence of } \\
0.5 \mathrm{~m} \text {; working } \\
\text { face supports } \\
\text { broken }\end{array}$ & $\begin{array}{l}\text { Accumulated } \\
\text { energy releasing } \\
\text { of coal pillar } \\
\text { induced hard } \\
\text { roof rupture }\end{array}$ & $\begin{array}{l}\text { Dynamic load } \\
\text { type }\end{array}$ & 4.56 \\
\hline 3 & Feb. 1, 2013 & $3.67 E+04$ & 30 & 50 & $\begin{array}{l}\text { Rib spalling of } \\
2 \mathrm{~m} \text {, many } \\
\text { working face } \\
\text { supports } \\
\text { broken, and one } \\
\text { day of } \\
\text { production stop }\end{array}$ & $\begin{array}{c}\text { Accumulated } \\
\text { energy releasing } \\
\text { of coal wall } \\
\text { induced hard } \\
\text { roof rupture }\end{array}$ & $\begin{array}{l}\text { Dynamic load } \\
\text { type }\end{array}$ & 3.22 \\
\hline 4 & $\begin{array}{l}\text { Mar. 15, } \\
2013\end{array}$ & $9.36 E+5$ & 30 & 40 & $\begin{array}{l}40 \mathrm{~m} \text { in front of } \\
\text { working face; } \\
\text { reduction rate of } \\
\text { return airway } \\
\text { section of } 100 \% \text {, } \\
\text { four people } \\
\text { dead, } 30 \text { days of } \\
\text { production stop }\end{array}$ & $\begin{array}{c}\text { Accumulated } \\
\text { energy releasing } \\
\text { of coal wall } \\
\text { induced hard } \\
\text { roof rupture }\end{array}$ & $\begin{array}{c}\text { Dynamic load } \\
\text { type }\end{array}$ & 9.27 \\
\hline 5 & $\begin{array}{c}\text { May 1, } \\
2013\end{array}$ & $5.78 E+5$ & 60 & 35 & $\begin{array}{l}\text { Reduction rate } \\
\text { of return airway } \\
\text { section of } 60 \%\end{array}$ & $\begin{array}{l}\text { Accumulated } \\
\text { energy releasing } \\
\text { of coal pillar } \\
\text { induced hard } \\
\text { roof rupture }\end{array}$ & $\begin{array}{c}\text { Dynamic load } \\
\text { type }\end{array}$ & 6.72 \\
\hline
\end{tabular}


TABLE 6: Rockburst damage potential classification.

\begin{tabular}{lc}
\hline RDE & Rockburst damage scale \\
\hline 0 to 3 & $R 0$ \\
3 to 5 & $R 1$ \\
5 to 7 & $R 2$ \\
7 to 9 & $R 3$ \\
9 to 10 & $R 4$ \\
\hline
\end{tabular}

\section{Disclosure}

The work contained in the paper was carried out as part of the of the project titled "Innovative Technologies and Concepts for the Intelligent Deep Mine of the Future ( $\mathrm{I}^{2}$ Mine)" under the 7th framework program of the European Union, which stresses on the need for a formal geotechnical risk assessment to be documented along with a proposed mining activity to justify its ability to tackle geotechnical accidents in underground mines.

\section{Competing Interests}

The authors declare that they have no competing interests.

\section{Acknowledgments}

This work is supported by the National Natural Science Foundation of China under Grant no. 51304126, New Teachers' Fund for Doctor Stations of Ministry of Education under Grant no. 20123718120009, the research fund for excellent young and middle-aged scientists of Shandong Province under Grant no. BS2013NJ007, Fok Ying Tung Education Foundation under Grant no. 141046, Shan Dong University of Science and Technology Outstanding Young Investigator Award under Grant no. 2014JQJH105, Shandong University of Science and Technology Graduate Innovation Fund no. YC150309, a Project of Shandong Province Higher Educational Science and Technology Program under Grant no. J15LH04, and State Key Laboratory of open funds under Grant no. SKLGDUEK1520. This paper was also supported by "the Tai'shan Scholar Engineering Construction Fund of Shandong Province of China".

\section{References}

[1] A. Kidybinski and J. Dubinski, Strata Control in Deep Mines, A. A. Balkema, Rotterdam, The Netherlands, 1990.

[2] C. Fairhurst, "Deformation, yield, rupture and stability of excavations at great depth," in Rockburst and Seismacity in Mines, C. Fairhust, Ed., pp. 1103-1114, A. A. Balkema, Rotterdam, The Netherlands, 1990.

[3] H. Manchao, X. Heping, P. Suping et al., "Study on rock mechanics in deep mining engineering," Chinese Journal of Rock Mechanics and Engineering, vol. 24, no. 16, pp. 2803-2813, 2005.

[4] D. H. Diering, "Ultra-deep level mining-future requirements," Journal of The South African Institute of Mining and Metallurgy, vol. 97, no. 6, pp. 249-255, 1997.
[5] R. G. Gurtunca and L. Keynote, "Mining below $3000 \mathrm{~m}$ and challenges for the South African gold mining industry," in Proceedings of the Mechanics of Jointed and Fractured Rock, pp. 3-10, Balkema, Rotterdam, Netherlands, 1998.

[6] D. H. Diering, "Tunnels under pressure in an ultra-deep Wifwatersrand gold mine," Journal of the South African Institute of Mining and Metallurgy, vol. 100, pp. 319-324, 2000.

[7] Y.-D. Jiang, Y.-S. Pan, F.-X. Jiang, L.-M. Dou, and Y. Ju, "State of the art review on mechanism and prevention of coal bumps in China," Journal of the China Coal Society, vol. 39, no. 2, pp. 205-213, 2014.

[8] P. P. Procházka, "Application of discrete element methods to fracture mechanics of rock bursts," Engineering Fracture Mechanics, vol. 71, no. 4-6, pp. 601-618, 2004.

[9] S. V. Tsirel' and N. V. Krotov, "Probability interpretation of indirect risk criteria and estimate of rock-burst hazard in mining anthracite seams," Journal of Mining Science, vol. 37, no. 3, pp. 240-260, 2001.

[10] E. Broch and S. Sørheim, "Experiences from the planning, construction and supporting of a road tunnel subjected to heavy rockbursting," Rock Mechanics and Rock Engineering, vol. 17, no. 1, pp. 15-35, 1984.

[11] M. K. C. Roberts and R. K. Brummer, "Support requirements in rockburst conditions," Journal of the South African Institute of Mining and Metallurgy, vol. 88, no. 3, pp. 97-104, 1988.

[12] L. M. Dou and X. Q. He, Rockburst Controlling Theory and Technology, China Mining University Press, Xuzhou, China.

[13] J.-F. Pan, Y. Ning, T.-T. Du et al., "The theory and system for preventing rock burst in large-scale areas," Journal of the China Coal Society, vol. 37, no. 11, pp. 1803-1809, 2012.

[14] M. T. Zhang, Z. H. Xu, Y. S. Pan et al., "A united instability theory on coal (rock) burst and outburst," Journal of China Coal Society, vol. 16, no. 4, pp. 48-53, 1991.

[15] T. Li, M.-F. Cai, J.-A. Wang, D.-C. Li, and J. Liu, "Discussion on relativity between rockburst and gas in deep exploitation," Journal of the China Coal Society, vol. 30, no. 5, pp. 562-567, 2005.

[16] M. C. He, Y. D. Jiang, and Y. X. Zhao, "Prevention theory of coalmine bumps based on the composite transformation mechanism," in Investigation on the Basic Theory and Engineering in Deep Reserves Mining, pp. 205-214, Science Press, Beijing, China, 2005.

[17] Y. S. Zhao, Z. C. Feng, and Z. X. Chang, "The least energy principle of dynamical rock failure," Chinese Journal of Rock Mechanics and Engineering, vol. 21, supplement, pp. 1931-1933, 2002.

[18] Q. F. Zhang, C. H. Zhou, H. Zhou, and K. Zhang, "Research on rock burst estimation and control measures for auxiliary tunnels in Jinping II hydropower station," Rock and Soil Mechanics, vol. 30, supplement 2, pp. 422-426, 2009.

[19] M. Janiszewski, Geotechnical risk assessment for selected underground mine with a focus on seismic risk [M.S. thesis], Aalto University, Espoo, Finland, 2014, https://aaltodoc.aalto.fi/handle/ 123456789/13897. 


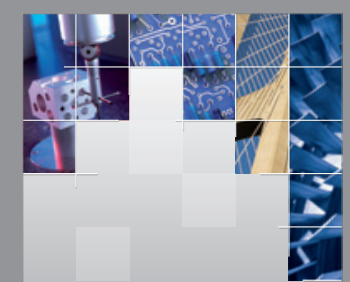

\section{Enfincering}
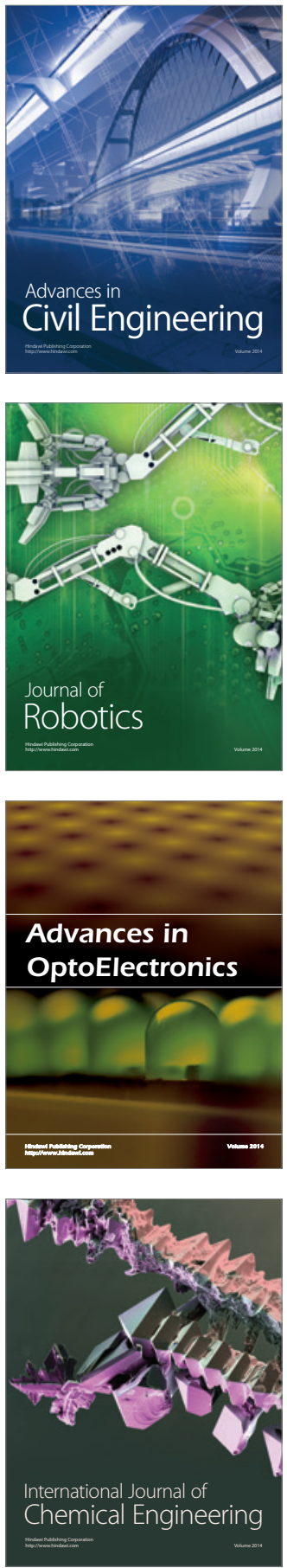

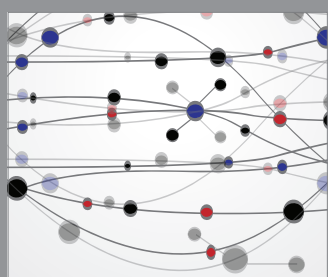

The Scientific World Journal

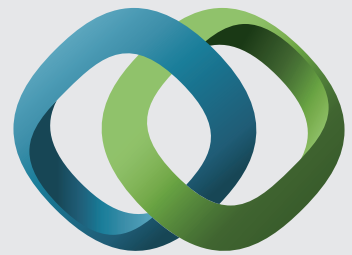

\section{Hindawi}

Submit your manuscripts at

http://www.hindawi.com
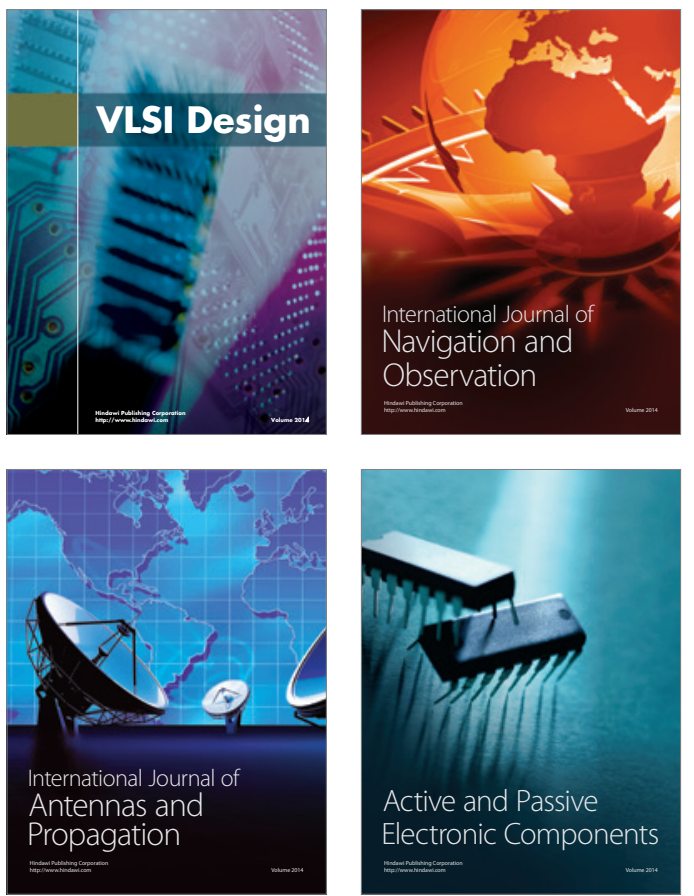
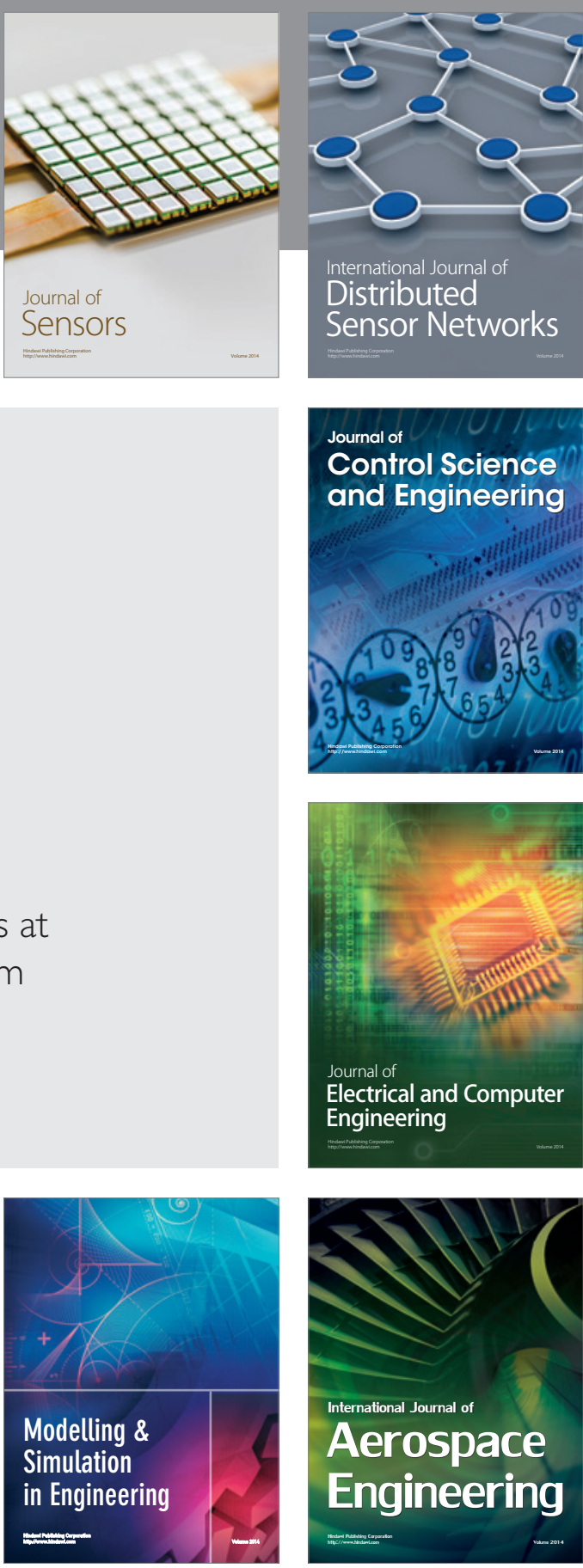

International Journal of

Distributed

Sensor Networks

Journal of

Control Science

and Engineering
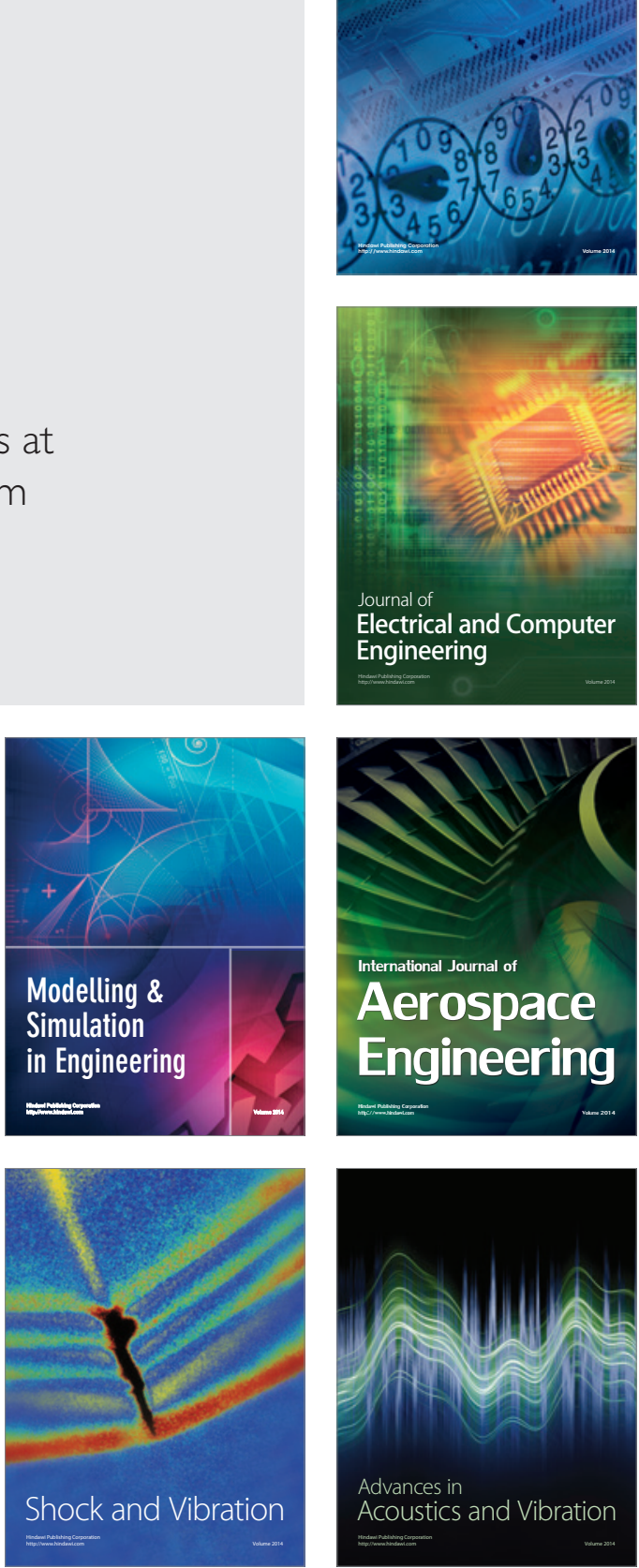